\title{
Melt evolution of the Finsch orangeite, South Africa
}

\author{
Henrietta Farr ${ }^{1}$, Andrea Giuliani ${ }^{1,2}$ and David Phillips ${ }^{1}$ \\ ${ }^{1}$ KiDs (Kimberlites and Diamonds), School of Earth Sciences, The University of Melbourne, Australia \\ ${ }^{2}$ ARC Centre of Excellence for Core to Crust Fluid Systems and GEMOC, Department of Earth and \\ Planetary Sciences, Macquarie University, Australia
}

\section{Introduction}

The Finsch diatreme is a diamondiferous orangeite with eight mapped units F1 - F8 (Fig. 1) ranging from diatreme facies volcaniclastic to hypabyssal intrusions. The F5 and F6 varieties occur as part of a precursor pipe termed the "southwest precursor" (SWPC), which is considered to have been emplaced just below the surface. The nature of the SWPC and its relationship to the main pipe remain enigmatic. Evolutionary trends in orangeites have previously been linked to variations in the abundance of olivine macrocrysts, a trend which also appears to influence the diamond grade in kimberlites. Point counting previously done by Fraser \& Hawkesworth (1992) indicated that the F5/6 units have up to twice the volume of macrocrystal olivine compared with F2/4; however, this does not take into account the proportion of magmatic and xenocrystic olivine.

A

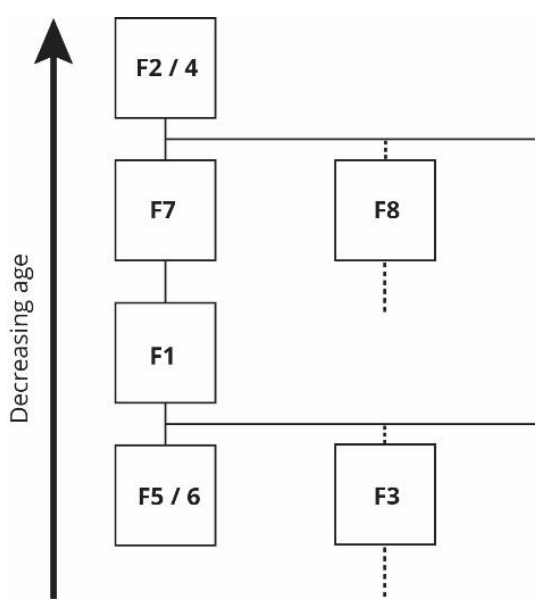

\section{B}

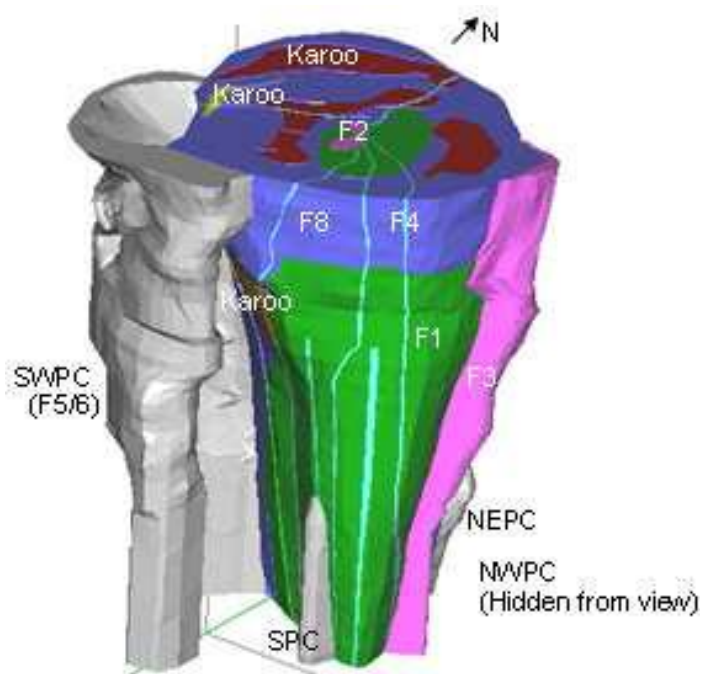

Figure 1: A) Proposed emplacement order of units in the Finsch diatreme modified from Clement 1982 and Fraser \& Hawkesworth 1992. B) 3-dimensional model from Rowlands 2008.

Samples from the F2, F6 and F8 units were examined for this study with F2 and F8 representing the "main pipe" and F6 the precursor. Additionally, as F2 occurs in the middle of the main pipe with late stage dykes radiating from this unit, it is thought that F2 represents the final stage of formation of the Finsch diatreme. F6 and F2 represent the earliest and latest significant magmatic activity at Finsch, respectively.

\section{Petrography}

Samples from the F2 (main pipe) and F6 units (SWPC) are both coherent orangeites. The mineralogy of F2 samples is dominated by phlogopite, olivine and diopside, whereas the F6 samples contain no diopside but abundant serpentine and carbonates and display a prominent segregationary texture. 
Compositionally distinct olivine populations occur in the two units. Samples from F6 contain significant amounts of magmatic olivine as overgrowths (up to $200 \mu \mathrm{m}$ thick) on xenocrystic cores, with rare grains composed of $>50 \%$ magmatic rim by volume. Olivine is commonly partially serpentinised with uncommon carbonate replacement for more altered grains. Mica from the F6 samples is extremely fine-grained and shows little $\mathrm{Al}$ depletion and $\mathrm{Fe}$ enrichment towards the rim.

The F2 samples contain abundant, partially resorbed but otherwise unaltered xenocrystic olivine in direct contact with the predominantly phlogopite, diopside groundmass. Phlogopite in F2 samples is zoned, exhibiting extreme $\mathrm{FeO}_{\text {tot }}$ enrichment (up to $25 \mathrm{wt} \%$ ) towards pure tetraferriphlogopite in the rims.

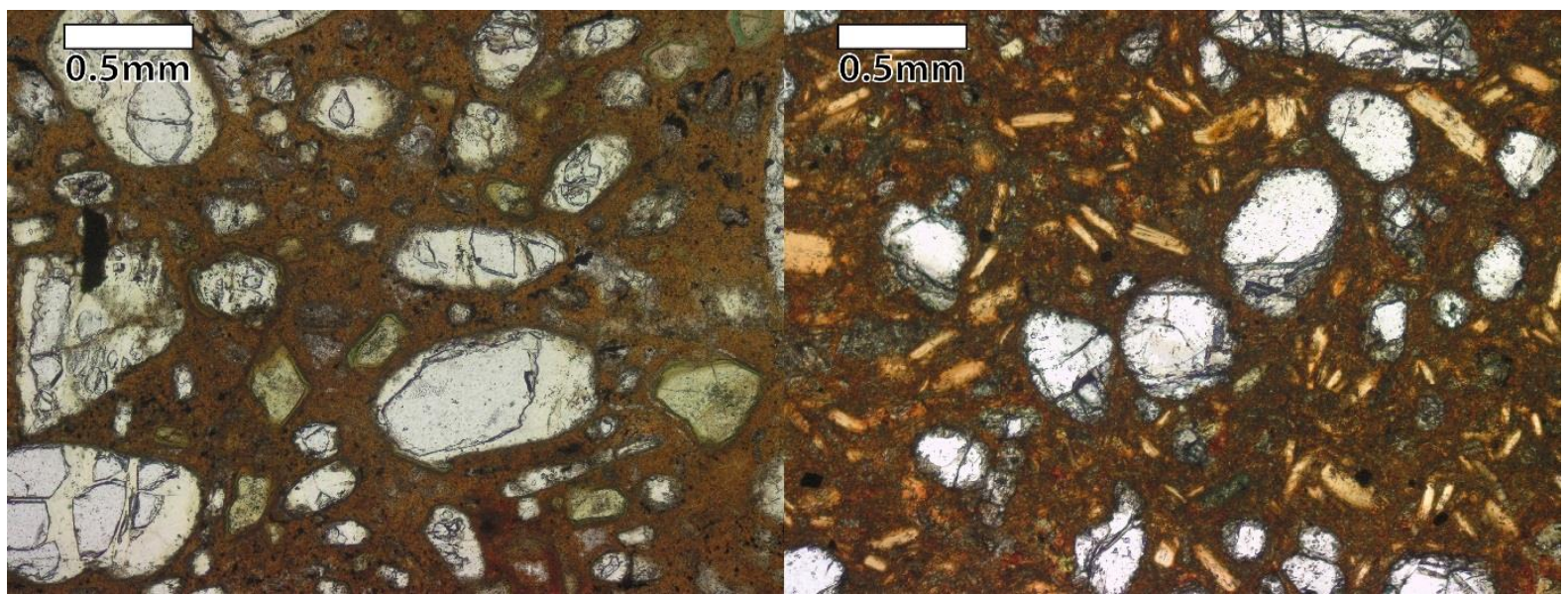

Figure 2: Photomicrographs of F6 (left) and F2 (right)

\section{Discussion}

The F5/6 precursor kimberlite has been generally interpreted as being hypabyssal in nature, however, more detailed analysis of the textures present suggests that these more coherent samples resulted from agglutination and sintering of the kimberlite upon emplacement (Rowlands 2008). This is consistent with emplacement at surface as a diatreme.

Despite the many differences in texture, the most striking difference between F6 and F2 is the lack of magmatic olivine in the latter. Although magmatic olivine in unit F2 may have been completely resorbed, it seems unlikely that it was present in similar quantities to F6 (rims up to $200 \mu \mathrm{m}$ in thickness) if at all. Additionally, significant differences in the alteration style of the olivine suggests that the late-stage fluids may have been distinct in chemical and physical characteristics for each unit.

This new data will be compared with existing whole rock and mineral chemistry from samples from the other Finsch units to highlight broader compositional and evolutionary trends. The effects of fractional crystallisation of olivine and other minerals will be re-evaluated within the framework provided by this textural and compositional information. Possible mechanisms involved in the evolution of the magma include varying degrees of partial melting of the same source and magmatic differentiation.

\section{References}

Clement CR (1982) A comparative geological study of some major kimberlite pipes in the Northern Cape and Orange Free State. PhD Thesis, University of Cape Town

Fraser KJ (1987) Petrogenesis of Kimberlites from South Africa and Lamproites from Western Australia and North America. PhD Thesis, The Open University

Fraser KJ, Hawkesworth CJ (1992) The petrogenesis of group 2 ultrapotassic kimberlites from Finsch Mine, South Africa Lithos 28:327-345 doi:http://dx.doi.org/10.1016/0024-4937(92)90013-O 
Rowlands T (2008) Proposed Emplacement Model for the Finsch Precursor Kimberlites. Masters Thesis, University of the Witwatersrand 